\title{
Process Re-design for Knowledge Service between Universities and Local Companies: From Interaction Perspective
}

\author{
Cong Zhang ${ }^{1, ~ a, ~ L i a n h u a ~ Z h u^{2, b} \text { and Liansheng Yang }}{ }^{3, \mathrm{c}}$ \\ ${ }^{1}$ No.2 Linggong Road, Ganjingzi District, Dalian City, Liaoning Province, P.R.C. \\ ${ }^{2}$ No.2 Linggong Road, Ganjingzi District, Dalian City, Liaoning Province, P.R.C. \\ ${ }^{3}$ No.2 Linggong Road, Ganjingzi District, Dalian City, Liaoning Province, P.R.C. \\ azc850426@163.com, ${ }^{\mathrm{b}} 15640438202 @ 163 . c o m,{ }^{\mathrm{c}} 187441002 @ 163 . c o m$
}

Keywords: KIBS, Knowledge-intensive Activity, Higher Education, Processing Innovation

\begin{abstract}
Knowledge services in universities result to strengthening local companies' competitiveness by knowledge utilization and creation. An effective service process leads to flexibility, reputation, high quality and creativity. The aim of this paper is to re-design the process of knowledge service after reveal the peculiarities of relationship between the suppliers and users. At first, it discusses the definition of knowledge service in universities; then, this article investigates the interactive relationship between the universities and local companies for a better understanding of the roles both play in the knowledge service process; finally, it proposes the re-designed process that shows how universities perform knowledge service to local companies.
\end{abstract}

\section{Introduction}

The importance of innovation through knowledge and knowledge services in modern economies has been testified by many scholars in different methods through decades. Simply to say, knowledge service is to provide knowledge. It is an activity which using knowledge as the core production element and by processing this resource to meet the needs of different groups or individuals. With a high degree of expert knowledge applying, this kind of activity creates add-value and provides innovation as the drivers, sources and carriers [1][2]. Universities, exist as cultural institutions since the Middle Ages, is an important knowledge service organization. Today universities have long been moved from the edge to the center of the society, and not only bear the functions of personnel training and scientific research, but its social service function which knowledge service is one of the most important means has become increasingly prominent. Since Miles et al. started their theoretical research on knowledge service, there have been an increasing studies and contributions in this academic field, both researchers and practitioners have noticed that knowledge service takes an essential part in the innovation system and plays an important role for the growth of regional economy [3][4].

In this article, we are going to take universities as an important kind of knowledge service organization and analyze the function of universities for the innovation of local companies. At first, we are going to discuss the definition of knowledge service in universities by elaborate the features of detailed meaning, significant characteristics and the specific contents that universities can help local companies to develop and innovate; second, this article investigates the interactive relationship between the universities and local companies for a better understanding of the roles both play in the knowledge service process; finally, it proposes the re-designed process that shows how universities perform knowledge service to local companies.

\section{Defining Knowledge Service in Universities}

Knowledge service is mainly concerned with supplying expertise knowledge and professionalism for other organizations for the purpose of developing a customized service or product solution to satisfy the client's needs, it is the service that involved economic activities which are intended to result in the creation, accumulation or dissemination of knowledge [5][6][7]. 
While it is debatable when concerns about knowledge service, we can summarize the understanding of knowledge service from many scholars into the following categories:(1) From a service perspective, a knowledge service is defined as an activity based on knowledge to meet the actual needs of customers; (2) From the operational level of knowledge, knowledge services can be decomposed into various specific operational processes; knowledge services are the process service of knowledge acquisition, analysis, integration, reorganization and et al.; (3) From the perspective of innovation, knowledge service is a value-added process and its ultimate goal is to create value for both the supplier and user.

By the discussion above, this article defines knowledge service as a value-added production activity with the process of knowledge operation in order to meet the different needs of customers. It emphasizes the nature of professionalism that knowledge service requires to focus on the aspects of mining, analysis, integration, reconstruction and innovation of knowledge which is strongly supported by the new technology; also it highlights the interactive innovation that knowledge production or knowledge flow is not a one-way direction it needs both supplier and customer to participate.

As an important knowledge service organization, the knowledge services provided by universities are based on the knowledge resources as the main production factors and using advanced scientific and technological means as supportive methods to transform knowledge to their clients to offer specific practical solution. As the most straightforward expression of social services function in universities, they make obvious contributions, which can directly involve with social economy and cultural construction. More specifically, the main features characterizing knowledge service are the following:

(1) Knowledge is the essential asset; which combines various types of highly specialized knowledge, both codified and tacit [8][9].

(2) Aim to develop specific problem solutions, which consist of transferring knowledge and skills to client organizations [10].

(3) The production of knowledge service requires frequent interactions and close cooperation between themselves and their clients [11].

Clearly being different from other knowledge services organizations, such as knowledge service enterprises, libraries and research institutions, knowledge services in universities must meet the requirements both from the societies and the university development itself, it must underline both knowledge and service parts.

(1) Knowledge resources are the prerequisite and basis for knowledge service. Knowledge services act as intermediaries between the client's knowledge base and the pool of codified knowledge [12]. Their main task is the creation and utilization of knowledge.

(2) Knowledge services accent to help clients to acquire new or deepen present knowledge. To meet the various needs of different customers which means not only knowledge services will satisfy their direct customers (where they get paid), but also they have to be a great help for the demanding of knowledge discovery, scientific research and talents (students) training for a sustainable development in universities. While providing these services, both universities and local companies mutually learn from each other through combining the existing knowledge, acquiring new explicit or tacit knowledge, as well as diffusing it [13].

\section{The Interactive Innovation: Analyze the Relationship Between Universities and Local Companies}

University knowledge services to the local economy are the content of joint training, common research that directly to provide scientific research to create add-value, it is a complex system, which involves many elements, links and complex mental activities. However, classify the content of knowledge services by the degree of innovation, the technical content and the degree of knowledge resource utilization, knowledge services in universities can be divided into collective 
knowledge collecting service, integrated knowledge integrating service and creative knowledge creating service.

Knowledge collecting service is the primary product of knowledge resources processing, mainly includes data analysis, information consultation, intelligence gathering and so on. For example, competitive intelligence collection can provide information about competitors and market environment for local companies that are as a basis for the development strategies making and development plans for new products or market. The knowledge integrating service is the pre-defined combination and optimization of knowledge resource to meet the needs of knowledge update. This kind of knowledge service is mainly short-term education and training program. Knowledge creating service mainly refers to the re-creation or discovery of knowledge, science and technology research. Science and technology play an important role in economic structure, economic growth and quality improvement, which makes scientific service is both essential and crucial in social economy. Universities have supreme experimental and equipment conditions and a large number of applied research teams with a wealth theoretical research foundation, which can become their creative knowledge creative service advantages.

From production purchase to production cooperate, in the pattern of universities as the innovation-promoting factor for local companies, the relationship between knowledge service supplier (university) and knowledge service user (local company) is diversified. Tordoir (1993) argues that knowledge service represents intermediaries between scientific and technological development and practical innovation which leading to the change of routines in companies. The motivations of local companies to seek help from knowledge service usually are for economic purposes and non-economic motives. Then Tordoir (1993) continues his research on the supplier-user relation, which includes: sparring, jobbing and selling [14]. The relationships of sparring is the most interactive one and selling only demands customers for purchasing knowledge service at a fixed price and barely participate in the interactive process.

In this study, according to the different degree of participation, there are three types of interactions between university and local companies during the knowledge service process. They are: direct purchase, cooperation and joint producing.

(1) Direct purchase. The local companies buy knowledge service at a pre-agreed price, such as information consultation. Often in this case, local companies are not involved in the producing phase only take part in the early stages of knowledge service. This kind of interaction makes the local companies are only able to receive the knowledge service passively, and applies for duplication purchase; low degree of original creation, simple service due to time constraints or high participation costs and service related to intellectual property protection or industry monopoly.

(2) Cooperation. In this relationship, local companies assist as resource sharing when necessary, such as short-term education and training. This type of role allows local companies to express their service needs details, cognitive changes and emotional reactions during the process of knowledge service. And the supplier of knowledge service-university is still the leader in the whole process, and requires perform exact and effective response at each interaction point.

(3) Joint producing. This relation emphasizes the important contribution of knowledge service user Local companies are involved in the whole process of knowledge service as a temporary employee of university, such as scientific and technology research and development. Under this division of type, local companies need to have a certain amount of service resources, and knowledge service supplier-university will assign part of the service tasks to local companies, and leave them to provide the necessary guidance. This kind of interaction should be based on the full understanding and highly trust of both sides of knowledge service suppliers and users.

\section{Process Re-design for a Better Knowledge Service Interaction}

Rationalizing products and simplifying the production process are important. Process re-design is to enhance the service ability and resources utilization rates under the continuous and effective interaction between the knowledge service suppliers and users, the universities and the local 
companies. Toni and Zipponi (1991) purposed that by simplification a traditional job shop can turn into a manufacturing system, and there are three areas of action to simplify the product and the process: product revision, process revision, revision of professional roles. In this part of the article we are going to pay our attention at the second area-process design. A well-designed working process can respond to various market demands or and can change quickly from one state to another. The process of knowledge service is the combination of design and marketing, production and industrialization.

Knowledge service is a complex system in which knowledge and knowledge-based applications are acquired at all stages of the service process. Process design is to maximize the effectiveness of knowledge service. The design of service process aims to improve the execution of knowledge service from concept design to product generation, and this standardized process is realized through the of interlocking task division construction. In the process of knowledge service, first through interpretation of requirement and the expression of service is to clear the demand for knowledge service; Then, on this basis, through the environmental framework and resource allocation to design knowledge services details; third, constructing resource base of knowledge service through the collection and complement of service resources; Then, it enters the core link of knowledge service- production. This is the stage of demanding achievement by using the methods of knowledge integration, optimization and creation. Finally, with the help of marketing and advanced IT technology, we can provide quick and customized knowledge service for local companies, which is the application process of knowledge service.

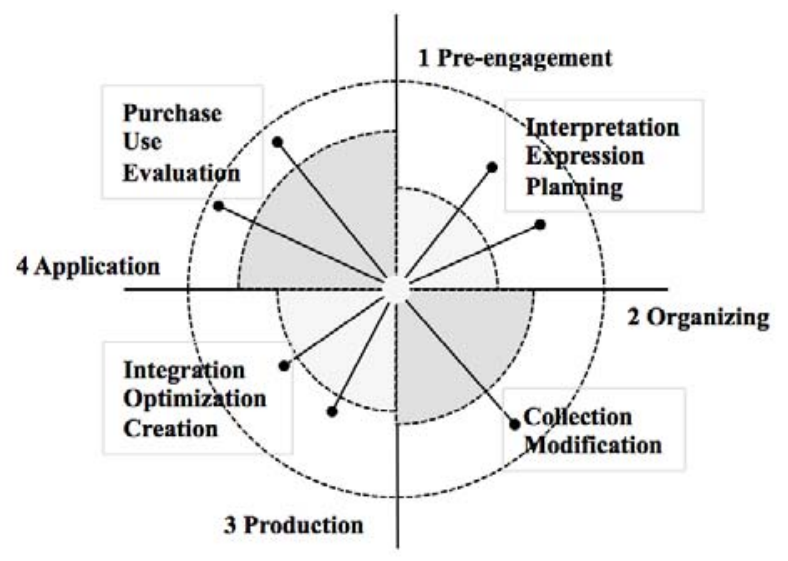

Fig.1. The Process of Knowledge Service

\section{(1) Stage 1:Pre-engagement}

This is the stage for setting a timetable of loading knowledge service, numbers of operations, kinds of tools and human resources and features of knowledge and technology. First, demand interpretation. The analysis of local companies' needs affect the overall effect of knowledge service. One way to interpret the demand for knowledge service is directly from the elaboration of local companies, the other way is through the analysis of potential requirements. The main contents of the demand interpretation are: customer, customer background and customer behavior. Second, service expression. In order to better accomplishment of knowledge service, university should build their knowledge service concepts according to the discipline background, product design background and knowledge application requirements. Third, the planning stage is fundamental for the performance of knowledge services, which is to divide the knowledge service into several dimensions, includes: knowledge domain expression, knowledge service product form, and resource application and operation process. By objecting the identification of manufacturing actions, university will reduce the number of components to assemble the service easily and quickly. Hewlett Packard personal computer was designed with 150 components during the manufacture process in its second version instead of the original 450 which gains optimization and more benefits [15]. 


\section{(2) Stage 2:Organizing}

This is the stage, the final preparation phase of knowledge service, aims to make ever service components functionally useful. It is the part of service resources assemble and service technology standardized. Greater specialization in technology and resources allows greater added value and high efficiency. First, under the per-designed service framework, university reaches out to collect all the resources that demanded, which refers to the university based on its own situation and actual needs of knowledge service to excavate related services resources. There are three ways for gathering: external selection, internal collection and to obtain necessary resources through strategic alliance partners. It is the basis and premise of carrying out knowledge service. Then, comes to the modification phase, in which university analyzes the original selected resources to find common features and simplify the data to improve process efficiency. Standardization and modification can lower management costs, reduce working defects and permit greater qualitative and productive characteristics.

\section{(3) Stage 3: Production}

After defining product characteristics and resources requirements, knowledge service in university to local companies comes to stage three-service production, which is the manufacturing system-building phase. This is the part allows tools, technology and expertise assembling. Actions in stage 3 are represented by knowledge integration, knowledge optimization and knowledge creation. The main task in this stage is to create new knowledge after integrate and optimize the original resources. It is the most intuitive way to display the knowledge service of universities, and the final result of knowledge service.

\section{(4) Stage 4: Application}

This is the layout phase which aims to structure flexible flow to make the knowledge service easier to commercialized. The degree of transportability determines the minimum movement batches, which limit production flexibility. Knowledge service transportability is an important variable that must be considered at this stage. Main tasks in this stage are knowledge service purchase, use and evaluate. With the escalation of technology and the change of market, the depreciation of knowledge service products has gradually accelerated, which requires the university to transfer the knowledge service product as soon as possible to obtain higher value and income. University needs to use certain means and ways to promote their knowledge services. Then, to ensure the quality of knowledge services, university needs to approach after-sales service. Product tracking, as an effective way of feedback, is the follow-up management of knowledge services. After feedback, it comes to the evaluation part. Under local companies purpose the usage of knowledge service products point out its advantages and shortcomings, universities modify, perfect or redesign knowledge service to improve the effectiveness and the functions of knowledge service.

\section{Conclusion}

This article has three contributions: First, it presents the specific concepts on the topic of knowledge service in universities that knowledge service as a value-added activity with the process of knowledge application in order to meet the different needs of users. Second, it argues three types of relationships in knowledge service for local companies to choose to help themselves to grow and innovate based on the different levels of intimacy. Third, new service concept and system for its realization leads to service innovation [16]. The article redesigns the process of knowledge service for universities to enhance the interactive relationship between universities and local companies and to create add-value and customer satisfaction.

\section{Acknowledgement}

In this paper, the research was sponsored by the National Social Science Foundation of China (Project No. BIA160139) and the Social Science Foundation of Liaoning Province (Project No. L12DGL032). 


\section{References}

[1] Dobrai, Farkas. Knowledge-intensive business services: a brief overview [J]. Perspectives of Innovations, Economics \& Business, 2009, (3) 15-17.

[2] EMCC, "Sector Futures. The KIBS Sector", European Monitoring Centre on Change. [Z] www.eurofound.europa.eu/emcc/content/source/eu06028a.html?p1=ef_publication\&p2=null, 2005.

[3] Cooke, P., Leydesdorff, L. development in the knowledge-based economy: the construction of advantage [J]. Technol Transfer, 2006, (31) 5-15

[4] Muller, E, \&, Zenker, A. Business Services as Actors of Knowledge Transformationn The Role of KIBS in Regional and National Innovation Systems [J]. Research Policy., 2001, (30) 1501-1516

[5] Bettencourt, L, A. Client Co- Production in Knowledge-Intensive Business Services, [J]. California Management Review, 2002, (44) 100-128

[6] Muller, E., \& Doloreux, D. (2009). What we should know about knowledge-intensive business services (KIBS).[J] Technology in Society: An International Journal, 2006,31(1) 64-72.

[7] Miles, I, Kastrinos, N, Flanagan, K, Bilderbeek, R, den, Hertog, P. Knowledge- intensive business services. Users, carriers and sources of innovation.[M]. Manchester: PREST, 1995.

[8] Schreyiogg, G., \& Geiger, D. The significance of distinctiveness: A proposal for rethinking organizational knowledge. [J] Organization, 2007, 14(1), 77-100.

[9] Koschatzky, K., \& Stahlecker, T. Structural couplings of young knowledge-intensive business service firms in a public-driven regional innovation system. [J] International Studies in Entrepreneurship, 2006:14, 171-193.

[10] Leiponen, A. Managing knowledge for innovation: The case of business-to-business services. [J] The Journal of Product Innovation Management, 2006:23, 238-258.

[11] Aslesen, H.W., \& Isaksen, A. (2007). Knowledge intensive business services and urban industrial development. [J] The Service Industries Journal, 2007,27(3), 321-338.

[12] Leiponen, A. Organization of knowledge exchange: an empirical study of knowledge-intensive business service relationships. [J] Economics of Innovation and New Technology, 2006,15(4/5), $443-464$.

[13] Koch, A., \& Strotmann, H. The impact of regional and functional integration on the post-entry performance of knowledge intensive business service firms.[C]44th Congress of the European Regional Science Association, 2004, University of Porto.

[14] P, P, Tordoir. The Professional Kowledge[D]. Amsterdam:University of Amsterdam, 1993. 1-1

[15] Schonberger, R.J., World Class Manufacturing: The Lessons of Simplicity Applied.[M] New York :The Free Press, 1986.

[16] Ojanen, V., \& Salmi, P., \& Torkkeli, M. Innovation Patterns in KIBS Organizations: A Case Study of Finnish Technical Engineering Industry.[C]Proceedings of the 40th Hawaii International Conference on System Sciences ,2007. 